\title{
The Measurement of Knowledge Construction in A Course of Diagnostic Evaluation of Learning Disorders in Psychology Students
}

\author{
Guadalupe Elizabeth Morales-Martinez, Michelle Garcia-Torres and \\ Maria del Carmen Castro-Gonzalez \\ National Autonomous University of Mexico, Mexico City, Mexico \\ https://orcid.org/0000-0002-4662-229X \\ https://orcid.org/0000-0003-1997-9274 \\ https:// orcid.org/0000-0001-5883-0857 \\ Yanko Norberto Mezquita-Hoyos \\ Autonomous University of Yucatán, Yucatan, Mexico \\ https://orcid.org/0000-0001-6305-7440
}

\begin{abstract}
This study evaluated the effects of academic learning on the organization and structure of a knowledge schema among psychology students. The authors designed three studies based on the Chronometric Constructive Cognitive Learning Evaluation Model. This article describes the first method of evaluation, which included a conceptual definition task based on the Natural Semantic Networks technique. The participants' task was to define ten target concepts using verbs, nouns, or adjectives as definers, and then rate the quality of each definer, taking into account the degree of semantic relationship between it and the target concept. The results suggest that the students' initial knowledge schema underwent modifications due to the restructuration of the cognitive structure of knowledge, the assimilation of new information nodes, and the elimination or establishment of new relationships between the conceptual nodes of the knowledge schema. The measurement of these cognitive expressions of academic learning through mental representation techniques can have relevant implications for cognitive characterization in student learning and the design of new teaching strategies that take account of the cognitive psychology principles of information processing underlying academic learning.
\end{abstract}

Keywords: learning evaluation; knowledge schema; cognitive construction; Natural Semantic Networks; psychology students 


\section{Introduction}

Twenty-first century society demands that students learn information as well as skills in order to be able to select and generate new knowledge from this information. The new educational models attempt to address these two types of learning, declarative and procedural, in their study programs. Meanwhile, new technologies have allowed innovation in teaching strategies for concepts and procedures using tools such as virtual reality and digital teaching platforms. However, there are few innovations in the field of learning assessment; furthermore, there are currently no instruments which measure all aspects of declarative and procedural learning (El-Yassin, 2015). To date, the predominant instruments in evaluation have been those that measure academic performance rather than learning process. These instruments are useful in terms of providing numerical indicators of a student's academic performance; however, these instruments measure the learning through a product without considering the context (Sadeghi \& Rahmati, 2017), nor do they measure the personal characteristics of students. In general, summative assessments do not take account of the fact that each student assimilates the knowledge they review in class in a very personal way, and therefore, there is a wide range of results from academic learning even with the same teaching quality and teaching conditions (Wiliam, 2011).

Arieli-Attali (2013) points out that teaching exclusively for performance deprives teachers of valuable information which would allow them to make decisions about how to modify their instructional techniques. Therefore, the academic community has begun to recognize that the cognitive needs and characteristics of the student are central elements in the design of the teaching-learning-evaluation cycle (Morales-Martinez et al., 2021). In this regard, the United Nations Educational Scientific and Cultural Organization (UNESCO, 2015) emphasizes that the design of learning evaluation tools demands a vision beyond knowledge measurement. Creating effective evaluation tools requires the purpose, scope, nature, impact, and level of the evaluation to be considered.

\section{The Chronometric Constructive Cognitive Learning Evaluation Model (C3-LEM)}

The incorporation of technologies within education has brought about advances in educational design and instruction. However, there is still a gap between these developments and innovation in terms of the methods used for assessing learning. Most of the contributions in this field are limited to a technological encapsulation of already existing evaluation strategies, and there are few evaluation proposals native to the digital age (Morales-Martinez, 2020). Additionally, Arieli-Attali (2013) points out that the available evaluation instruments provide information on specific moments. Thus, it is not possible to obtain a complete picture of the continuous progress of a student's learning process; therefore, it is difficult for the results obtained from these assessments to help improve a wide spectrum of aspects of teaching. Furthermore, given the nature of these instruments, it is difficult to obtain information on the essential cognitive aspects of learning. For example, there is scarce information about the ways in which students organize information, represent problems, select, and use learning strategies, and make use 
of self-control skills. All these aspects are of relevance if we take into account that fact that students live in a society with an economy based on the processing of information. One way to approach this educational challenge is to use cognitive technology to design new methods for evaluating learning.

Cognitive psychology includes a wide range of techniques used to create instruments that provide information about the state of a student's knowledge, before, during, and after a course. For example, Lopez-Ramirez and MoralesMartinez (2019), Lopez et al. (2014), Morales \& Lopez (2016), Morales-Martinez, Lopez-Perez, et al. (2020), Morales-Martinez et al. (2021), Morales et al. (2017) and Morales-Martinez et al. (2015) have proposed the Chronometric Constructive Cognitive Learning Evaluation Model (C3-LEM), which suggests the use of cognitive tools to measure the cognitive properties of knowledge schemas learned in an academic environment. For example, this model measures what content is in a student's memory, how it is organized and structured, the temporal and dynamic patterns of these knowledge structures, and other aspects of a student's knowledge state.

The C3-LEM obtains the learning indicators in two phases in the evaluation (Figure 1). The first phase is the constructive cognitive evaluation, whose main objective is to measure the changes in the organization, structure, and cognitive dynamics of a student's knowledge schema, which are assumed to be due to the learning produced by the course. The second phase involves the chronometric cognitive evaluation of the changes that occur in the temporal patterns of schematic behaviour and that are a measure of the degree of consolidation of the schema in each student's long-term memory.

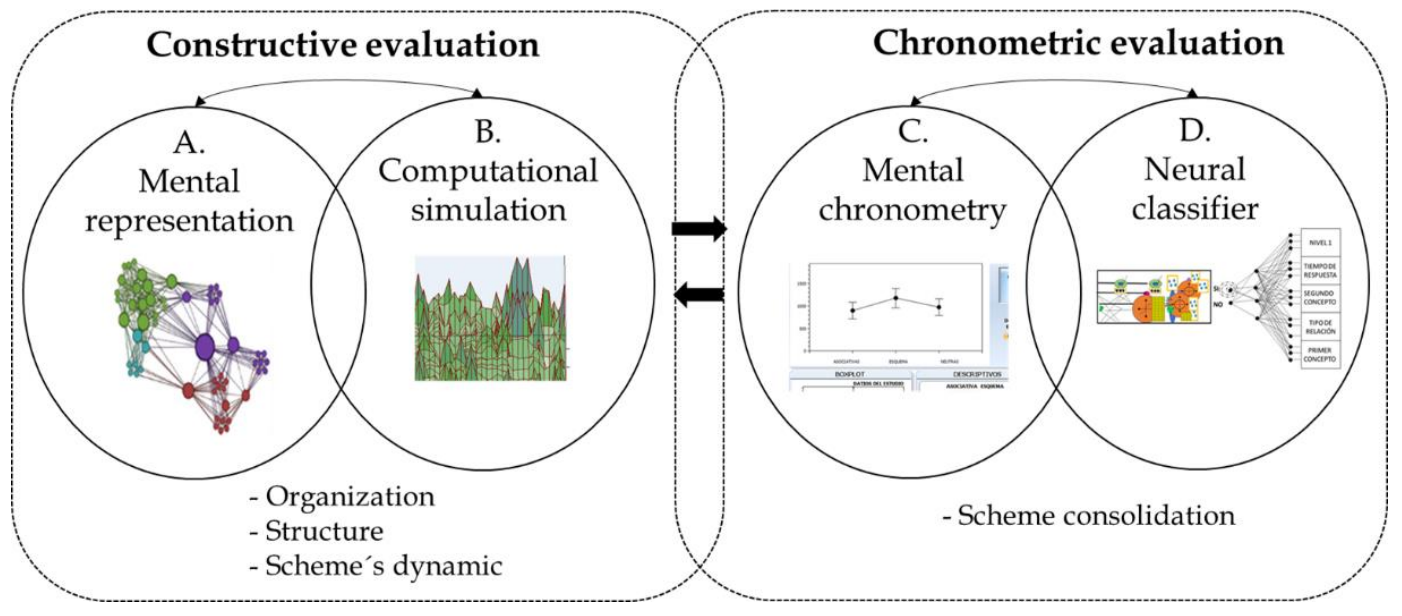

Figure 1: The two phases and components of the C3-LEM

Note: From "Cognitive e-tools for diagnosing the state of medical knowledge in students enrolled for a second time in an anatomy course", by Morales-Martinez, AngelesCastellanos, et al. (2020), International Journal of Learning, Teaching and Educational Research, 19(9), p. 346 (https:/ / doi.org/10.26803/ijlter.19.9.18). Copyright 2020 by the authors and IJLTER.ORG.

Overall, this evaluation model provides information about conceptual advances throughout academic training. To this end, the C3-LEM takes into account the 
principles and laws of human processing based on two approaches to cognitive psychology: the theory of human information processing or HIP and the theory of parallel distributed processing or PDP. Since, in this paper, the main objective is to explore the cognitive construction of the knowledge schema, the following section focuses on some of the cognitive principles of knowledge construction from these two approaches.

\subsection{The Cognitive Principles of Knowledge Construction}

From HIP, students' minds build cognitive schemas with the motor, procedural and declarative information that they learn and store in their memories throughout a course or career. Here, declarative schemas are of particular interest since, in an academic learning context, students create knowledge networks about what they learn from the semantic and conceptual information on the course. HIP posits that semantic knowledge networks are made up of information nodes (concepts) and relational links among these concepts. The organization and structure of these nodes and relational links enable the students to give a psychological meaning to their knowledge. In this regard, Figueroa-Nazuno (2007) mentions that each person creates a meaning of the world by constructing or reconstructing the knowledge schemas in their memory beyond free association.

The authors of this paper define meaning construction as a cognitive process through which students obtain a personal vision of their knowledge. In an academic environment, meaning results from interaction among the cognitive and emotional characteristics of students and their context and learning experiences. Then students can create meaning or modify the meaning of their knowledge by constructing or reconstructing their cognitive structure throughout an academic learning process. Thus, learning experiences produce changes in the students' cognitive structure.

From the cognitive psychology point of view, the degree to which students can modify their knowledge structures depends on the flexibility and stability of their schemas. According to Lopez-Ramirez and Morales-Martinez (2019) schematic flexibility refers to the malleability of cognitive structure. It means the degree to which the cognitive structure can be reorganized or reconfigured without being destroyed during the assimilation of new information. On the other hand, these authors define schematic stability as the degree to which the cognitive structure can hold its cognitive configuration and organization after assimilating new information.

The academic development level of students influences the cognitive flexibility and stability of knowledge schemas. Generally, students who begin their learning process in a new field of knowledge have a pre-schema with a vague organization and a structure that is not very clear (Morales-Martinez et al., 2017). The authors of this paper have hypothesized that this kind of initial cognitive structure could be modified more easily than schemas which are completely organized and configured. Furthermore, grasping the level of organization and structure of knowledge schemas provides information about the learning needs that a student 
might have. According to Messick (1984), the academic objective for beginners with incipient cognitive structures of knowledge should be the assimilation of new knowledge. Thus, the learning evaluations must measure the recognition or retrieval of information in order to be consistent with this first academic level. In contrast, students at an advanced level of academic development require teaching strategies and assessments that promote the restructuring of the schemas and the use of these schemas in problem-solving.

Since the learning needs of beginners are quite different from those of advanced students, it is necessary to diagnose their academic development level. To this end, it is helpful to consider Marzano and Pickering's learning model (1997) because it proposes three learning dimensions which are directly related to the development of cognitive structures of knowledge, namely: the acquisition and integration of knowledge; extending and refining knowledge; and the meaningful use of knowledge. The first two dimensions are especially linked to this research work, and this was the focus of this study.

According to Marzano and Pickering (1997), the acquisition and integration of declarative knowledge require that students store information (facts, concepts, and principles) in their memory, deliberately and consciously. Additionally, this learning dimension involves meaning construction by linking old and new knowledge. Another component of this dimension is information organization. In order to acquire declarative knowledge, students must look for relational patterns within the information. In contrast, extending and refining knowledge refers to discovering new perspectives about the knowledge or establishing new links within information by comparing, classifying, analyzing, or reasoning.

In this work, the authors interpreted these two learning dimensions from the perspective of the mental representation of knowledge. The acquisition of knowledge implies incorporating new nodes of information in students' memories regardless of the organization of these concepts. Knowledge integration requires the formation of meaning based on the organization of information stored in the memory (e.g., the priority of recall of new nodes, the general patterns of recall). Extending and refining knowledge entails incorporating more specialized and accurate concepts to theorize each knowledge domain, establishing new relationships among conceptual nodes of the knowledge schema, forming new knowledge structures, or creating innovative inferences from the information stored in the memory.

All these aspects of the cognitive construction of knowledge can be measured throughout the constructive cognitive evaluation, which provides evidence about the type of information that students choose as relevant, the way they organize and structure it to build their knowledge, and their academic development. This is illustrated in the next section.

\subsection{Advances in the Cognitive Assessment of Knowledge Construction}

When students enroll on a course, teachers and the education system expect them to learn by undergoing the experiences designed specifically for that purpose. 
Constructive cognitive evaluation allows the changes in students' knowledge schema produced by the learning experiences to be measured. This kind of assessment involves applying a mental representation technique and computational simulations (Morales-Martinez et al., 2021; Morales-Martinez, Angeles-Castellanos, et al., 2020; Morales-Martinez, Lopez-Perez, et al., 2020). In this regard, the C3-LEM uses Natural Semantic Networks (NSNs) to explore the mental representation of academic knowledge. The NSNs give information about how persons construct their own meaning of the world during a process of memory construction and reconstruction of the knowledge that is stored in their memory (Figueroa-Nazuno, 2007; Figueroa et al., 1976).

From a C3-LEM perspective, the main purpose of NSNs is to discover the meaning that students give to the knowledge that they learn on academic courses. Furthermore, since this technique could be applied at different points in time during the academic course, it is possible to obtain a fluid understanding of the cognitive dynamic of construction of knowledge schemas. Students modify their declarative knowledge schemas endlessly by assimilating the information they consider relevant from the material they review throughout the course. Consequently, the construction of meaning from knowledge is a continuous process through time. The result of this learning process depends upon various factors as the prior knowledge that a student has at the beginning of a course (Morales-Martinez, Lopez-Perez, et al., 2020; Urdiales-Ibarra et al., 2018; MoralesMartinez et al., 2021), the student motivation to learn, the cognitive functioning level on which the course focuses (Morales, 2020), the distribution of topics during the course and the importance assigned to each topic (Morales-Martinez, AngelesCastellanos, et al., 2020).

The NSNs are helpful in detecting the characteristics and cognitive changes that the schemas undergo due to learning at different time points within an academic year. In this regard, Morales-Martinez, Lopez-Perez, et al. (2020) observed that psychology students seem to begin the courses with a pre-schema. However, these pre-schemas do not show a clear organization among their information nodes. After the course, students have learned new information nodes, eliminated other nodes, and established new relationships between the nodes they assimilated from the course. These changes are specific indicators that the student has experienced a learning process due to the academic experiences during the course (Morales-Martinez et al., 2021). In addition, the NSNs technique has made it possible to identify difficulties in the integration of information in a unified schema in students with low academic performance and in beginners, when learning a topic (Morales-Martínez, Mezquita-Hoyos, et al., 2018; MoralesMartinez, Angeles-Castellanos, et al., 2020; Morales-Martinez, Lopez-Perez, et al., 2020; Urdiales-Ibarra et al., 2018). Furthermore, Morales-Martinez, AngelesCastellanos, et al. (2020) applied this technique to explore the formation of the anatomy schema in medicine students and they discovered that other factors could affect schema configuration in the minds of students, for example the difficulties associated with academic performance, the level of academic development of students, and the emphasis and distribution of the topics to be reviewed. 
The NSNs can provide information on the effectiveness of corrective learning strategies. Using this tool, Morales-Martinez, Mezquita-Hoyos, et al. (2018) observed that engineering students who did not achieve passing grades in a computational usability course could integrate the knowledge schema in this subject after attending a remedial course. Bearing in mind that NSNs are very useful for assessing several aspects of learning, Morales-Martinez, TrejoQuintana, et al. (2021) used this technique to explore the cognitive properties of knowledge acquisition on human cognition in psychology students. These authors observed that students with previous information about the evaluated topic have a cognitive pre-schema of knowledge. However, the pre-schemas of advanced students could be different in terms of the content quality, organization, and cognitive structure of knowledge from those of beginners, namely students who are enrolled on a course for the first time (Morales-Martinez, Lopez-Perez, et al., 2020). This result suggests that the changes in knowledge structure are qualitatively different depending upon the expertise of the students. Additionally, the cognitive properties of pre-schemas seem different between beginners and advanced students. Since there are very few studies based on this cognitive approach, it is necessary to provide empirical evidence on the learning properties of knowledge schemas based on the academic development level of different students.

Assuming that students with expertise on a topic demonstrate better organization and structure in the knowledge schema than beginner students, the present research work explored if the cognitive structure of the diagnostic evaluation for learning disorders schema in participants in this study was well-organized and structured since students had been enrolled on previous courses on this topic. If the students had a pre-schema based on their expertise in the diagnosis and learning disorders, then, it was expected, that their pre-schema would include well-organized information and a schema configuration which was clearly integrated as observed in the study by Morales-Martinez, Trejo-Quintana, et al. (2021). In brief, this work aims to broaden our understanding of the scope of this technique in a different domain of knowledge and provide more evidence about the cognitive characteristics of knowledge schema in students with some expertise in a topic.

\section{Method}

In this research work, the present authors explored the changes in the knowledge schema that psychology students underwent during a course on the diagnostic evaluation of learning disorders. In order to achieve this, the organizational and structural properties of the students' knowledge schema were measured throughout the NSNs. This technique is based on a cognitive view of the mental representation of knowledge. From this approach, students form a cognitive structure of the information that they learn during academic courses. NSNs is a tool for observing the cognitive characteristic of such knowledge. In this study, the main objective was to observe the organization, structure, and dynamic properties of the cognitive schemas of knowledge in a group of psychology students. 


\subsection{Sample}

The participants were 43 undergraduate students enrolled in the 5th semester of psychology (91\% female and 9\% male). Their ages ranged between 18 and 25 years old $(M=19.7, S D=1.30)$. Participants were chosen based on purposive sampling. Participation was voluntary, and the teacher awarded points to the students for their participation. The participants belonged to two different groups; since these groups were each made up of a small number of students, the teaching conditions for each class (time exposure, readings, activities) were the same, and the same teacher taught the topics within the same context, and academic period; thus, the researchers integrated the participation of both groups within a single data set.

\subsection{Instruments and Materials}

The authors designed the NSNs instrument using the Protocol for the Collection of Target Concepts and Central and Deferred Definers (Morales-Martinez, 2015). This protocol provides directions to the researcher to help the teacher identify the ten target concepts for a course. In this study, the target-identified concepts were development, psychomotor, learning, dyslalia, dyslexia, dyscalculia, attention deficit, evaluation, diagnosis, and reporting. The presentation of the target concepts of the study required the use of EVCOG software. This software allows the design, application, capture and analysis of the data for cognitive studies for the C3-LEM (Morales-Martinez, Angeles-Castellanos, et al., 2020) (Morales-Martínez and López-Ramirez, 2018 a, b, c, d).

\subsection{Research Design}

This research employed a quasi-experimental design. The authors applied the NSNs technique before and after the course to explore the changes in the schema, for the diagnostic evaluation of learning disorders, produced by the learning process undertaken on the course. The study involved a definitional task to recover the main conceptual nodes related to the evaluated knowledge schema.

\subsection{Procedure}

The study comprised two stages; during the first one, the authors informed the participants about the objectives, the procedure, and the benefits of participating in the study. In this informative stage, the students who decided to participate voluntarily gave their informed consent. In the second stage, the students received instructions, practiced the NSNs task and answered the final study. The task was to define ten target concepts using verbs, nouns, adjectives, and pronouns as definers. Each objective had to be defined within 60 seconds, and then the participants rated the definers using a scale from 1 to 10 . Low scores meant that the quality of the word as a definer was low, and high scores indicated that the definer was significantly related to the target. Three essential restrictions delimited this task; the first was that the targets had to be defined based on the course content; that is, free association was ruled out. The second one restriction was that there was a pre-established time for defining each concept (60 seconds). Finally, the targets were presented at random. The application time oscillated between 15 and 20 minutes. The NSNs task was carried out twice, at the beginning and the end of the course. 


\section{Data Analysis}

The authors examined the data using two analysis approaches. The first one was the conventional NSNs analysis of the participant data using the EVCOG. This analysis implies the computation of organization and structure indicators proposed by Figueroa et al. (1976) and modified by Lopez (1996) and Lopez and Theios (1992). First, semantic richness (J value) was computed as the number of different definers in each target concept. Semantic weight ( $\mathrm{M}$ value) was calculated as the quality degree estimated by participants considering the semantic relationship between the definer and target. The SAM group (Semantic analysis of $\mathrm{M}$ ) was made up of the ten definers with the greatest semantic weight for each target concept. The semantic density ( $G$ value) was computed by the closeness score between the concepts of the network. In addition, the authors calculated the inter-response time (IRT), which is the time that student needed to recover and write a definer. Furthermore, the authors computed the percentage of concepts appearing in the initial SAM groups as well as in the final ones (the conceptual constancy or CC Value). Also, the conceptual valuation consistency (CVC Value) was computed taking into account the similarity percentage between the weights assigned to the definers that were constant at the beginning and the end of the course in each SAM group. This indicator is a modification of the $Q$ value of Figueroa et al. (1976) that measures the percentage of similarity in the hierarchies of the common definers between two semantic networks.

The second analysis was qualitative and was based on a visual inspection of the organization and structure of the concepts through a GEPHI analysis (Bastian et al., 2009). This analysis first required the SASO matrix (matrix of the semantic analyzer of schemata organization) to be extracted; it is a matrix of association weights among the concepts of the NSNs (Lopez, 1996; Lopez \& Theios, 1992). Then, the researchers extracted the SASO matrix by calculating the probability of co-occurrence between the concepts with the following formula:

$$
W_{\text {IJ }}=-1 n\left\{[p(X=0 \& Y=1) p(X=1 \& Y=0)]^{*}[p(X=1 \& Y=1) p(X=0 \& Y=0)]^{-1}\right\}[1]
$$

The EVCOG system allows the automatic calculation of the association weight (WIJ) between the concepts ( $\mathrm{X}$ and $\mathrm{Y}$ ). This software calculates the probability of co-occurrence between the pairs of concepts. First, the program calculates the joint probability that $\mathrm{Y}$ appears, but $\mathrm{X}$ does not appear in a SAM group $\mathrm{p}(\mathrm{X}=0$ \& $\mathrm{Y}=$ $1)$. The procedure is similar for each element of the formula. However, the calculation of $\mathrm{p}(X=1 \& \mathrm{Y}=1)$ involved estimating the hierarchical modulation of M-values in SAM groups. Finally, the authors fed the GEPHI software with the SASO connectivity matrix to visualize the schema (see Figure 4).

\section{Results}

Three aspects were analyzed through the NSNs data. First, the authors determined what kind of information fitted into the initial knowledge schema of students and how this information had changed at the end of course in the students' memories. The second aspect was to explore the changes in the dynamic of connection among the main conceptual nodes (targets). Finally, it was carried on an inspection of the structure and organization of concepts and structure schema was carried out, through a visual representation of NSNs. 


\subsection{Results from NSNs Analysis}

The analysis considered the NSNs indicators described by Lopez and Theios (1992). Tables 1 and 2 present the NSNs indicators (frequency, IRT, M, F, J, and G value) that the participants obtained at the beginning and the end of the course. Also, there were changes in the content and number of conceptual nodes through the NSNs (Tables 1 and 2). In this respect, the J value increased for each target towards the end of the course. This result means the students showed an increase in the semantic richness of their knowledge structure which was linked to the course. The increase was not homogeneous across the targets, however. Dyscalculia was the target with the most significant increase in the number of definers, followed by report. Moreover, diagnosis and learning were the targets with the smallest increase in the number of definers.

Table 1. SAM groups at the beginning of the course

\begin{tabular}{|c|c|c|c|c|c|c|c|c|c|c|c|}
\hline \multicolumn{4}{|c|}{ Development } & \multicolumn{4}{|c|}{ Psychomotor } & \multicolumn{4}{|c|}{ Learning } \\
\hline $\mathbf{F}$ & Definidor & $\mathbf{M}$ & TIR & $\mathbf{F}$ & Definidor & $\mathbf{M}$ & TIR & $\mathbf{F}$ & Definidor & $\mathbf{M}$ & TIR \\
\hline 1 & Growth & 224 & 20 & 1 & Movement & 276 & 19 & 1 & Knowledge & 153 & 20 \\
\hline 4 & Learning & 97 & 28 & 1 & Motricity & 116 & 16 & 1 & Memory & 97 & 26 \\
\hline 1 & Evolution & 81 & 22 & 1 & Body & 97 & 21 & 2 & School & 88 & 22 \\
\hline 1 & Physical & 77 & 39 & 2 & Development & 86 & 36 & 2 & Attention & 68 & 28 \\
\hline 1 & Maturation & 73 & 25 & 3 & Skills & 76 & 32 & 2 & Development & 64 & 34 \\
\hline 1 & Stages & 72 & 28 & 1 & Brain & 69 & 28 & 3 & Skills & 52 & 32 \\
\hline 1 & Go forward & 57 & 29 & 1 & Mind & 54 & 24 & 1 & Study & 51 & 20 \\
\hline 3 & Skills & 50 & 28 & 3 & Kids & 47 & 41 & 2 & Information & 50 & 32 \\
\hline 1 & Psychological & 49 & 29 & 1 & Motor & 40 & 28 & 1 & To learn & 39 & 14 \\
\hline \multirow[t]{3}{*}{1} & Process & 40 & 19 & 1 & Psychology & 37 & 14 & 1 & Education & 38 & 22 \\
\hline & Valor J: 220 & \multicolumn{2}{|c|}{ Valor G: 18.40} & & Valor J: 201 & \multicolumn{2}{|c|}{ Valor G: 23.90} & & Valor J: 235 & \multicolumn{2}{|c|}{ Valor G: 11.50} \\
\hline & \multicolumn{3}{|c|}{ Dyslalia } & \multicolumn{4}{|c|}{ Dyslexia } & \multicolumn{4}{|c|}{ Dyscalculia } \\
\hline $\mathbf{F}$ & Definidor & M & TIR & F & Definidor & 197 & TIR & $\mathbf{F}$ & Definidor & M & TIR \\
\hline 2 & Language & 194 & 13 & 5 & Disorder & 136 & 14 & 2 & Numbers & 161 & 14 \\
\hline 5 & Disorder & 148 & 24 & 2 & Words & 130 & 18 & 1 & Math & 132 & 26 \\
\hline 1 & Speech & 139 & 23 & 2 & To read & 129 & 26 & 5 & Problems & 104 & 18 \\
\hline 2 & Words & 116 & 22 & 5 & Problems & 120 & 16 & 5 & Disorder & 93 & 29 \\
\hline 3 & Difficulty & 99 & 20 & 1 & Letters & 111 & 18 & 4 & Learning & 78 & 39 \\
\hline 5 & Problems & 89 & 17 & 1 & Writing & 108 & 33 & 3 & Difficulty & 55 & 20 \\
\hline 1 & Pronunciation & 71 & 35 & 1 & Confusion & 84 & 32 & 1 & Addition & 46 & 34 \\
\hline 1 & Phonemes & 62 & 44 & 2 & Language & 76 & 27 & 1 & Operations & 44 & 39 \\
\hline 2 & To read & 51 & 25 & 2 & Numbers & 51 & 29 & 1 & Subtraction & 40 & 33 \\
\hline \multirow[t]{2}{*}{2} & Tongue & 48 & 38 & 3 & Kids & 50 & 34 & 2 & School & 31 & 31 \\
\hline & Valor J: 233 & \multicolumn{2}{|c|}{ Valor G: 14.60} & & Valor J: 233 & \multicolumn{2}{|c|}{ Valor G: 8.60} & & Valor J: 171 & \multicolumn{2}{|c|}{ Valor G: 13.00} \\
\hline \multicolumn{4}{|c|}{ Attention-deficit } & \multicolumn{4}{|c|}{ Evaluation } & \multicolumn{4}{|c|}{ Diagnosis } \\
\hline $\mathbf{F}$ & Definidor & M & TIR & $\mathbf{F}$ & Definidor & M & TIR & $\mathbf{F}$ & Definidor & $\mathbf{M}$ & TIR \\
\hline 1 & Distraction & 147 & 31 & 2 & Tests & 153 & 25 & 2 & Evaluation & 172 & 17 \\
\hline 5 & Problems & 141 & 24 & 1 & To rate & 136 & 24 & 2 & Tests & 99 & 30 \\
\hline 5 & Disorder & 120 & 21 & 1 & Diagnosis & 92 & 21 & 1 & Result & 58 & 20 \\
\hline 3 & Kids & 101 & 27 & 1 & Exam & 85 & 21 & 5 & Problems & 51 & 38 \\
\hline 1 & Hyperactivity & 96 & 21 & 1 & Knowledge & 70 & 22 & 5 & Disorder & 50 & 24 \\
\hline 1 & Concentration & 61 & 32 & 4 & Learning & 59 & 31 & 1 & Interview & 49 & 29 \\
\hline 4 & Learning & 54 & 35 & 1 & Revision & 44 & 43 & 1 & Patient & 46 & 32 \\
\hline 1 & Lack of attention & 52 & 38 & 2 & Questions & 42 & 39 & 1 & Treatment & 46 & 43 \\
\hline 2 & Attention & 46 & 37 & 3 & Results & 36 & 24 & 2 & Questions & 34 & 30 \\
\hline \multirow[t]{3}{*}{3} & Difficulty & 38 & 21 & 1 & To know & 29 & 49 & 3 & Results & 33 & 22 \\
\hline & Valor J: 198 & Val & 10.90 & & Valor J: 207 & Valo & s: 12.40 & & Valor J: 217 & & : 13.90 \\
\hline & $\mathbf{R e}_{\mathbf{F}}$ & & & & & & & & & & \\
\hline $\mathbf{F}$ & Definidor & M & TIR & & & & & & & & \\
\hline 1 & A text & 180 & 23 & & & & & & & & \\
\hline 2 & Information & 113 & 22 & & & & & & & & \\
\hline 1 & Investigation & 76 & 25 & & & & & & & & \\
\hline 1 & Reading & 67 & 37 & & & & & & & & \\
\hline 2 & Evaluation & 62 & 26 & & & & & & & & \\
\hline 1 & Summary & 61 & 29 & & & & & & & & \\
\hline 1 & Data & 57 & 22 & & & & & & & & \\
\hline 1 & Essay & 45 & 37 & & & & & & & & \\
\hline 1 & Conclusion & 43 & 40 & & & & & & & & \\
\hline 3 & Results & 43 & 35 & & & & & & & & \\
\hline
\end{tabular}


In contrast, the reader can observe in Table 2 that the participants eliminated information nodes that appeared in the first phase, and they also included new information nodes in each SAM group. For example, the target $d y$ slalia presented a CC value of $90 \%$ for the NSNs; nine of the ten initial concepts remained in the final NSNs (language, disorder, speech, words, difficulty, problems, pronunciation, phonemes, reading), while one of them was eliminated (language). Thus, a new concept (articulation) was assimilated in the SAM group towards the end of the course. On the other hand, evaluation had a CC value of 30\% for the NSNs. Of the ten initial concepts, only three concepts (tests, diagnosis, exam) appeared again in the final SAM group, while seven concepts (qualify, knowledge, learning, review, questions, results, know) were eliminated and in their place appeared seven new concepts (treatment, interviews, observation, diagnosis, psychological, analysis, evaluate).

Table 2. SAM groups at the end of course

\begin{tabular}{|c|c|c|c|c|c|c|c|c|c|c|c|}
\hline \multicolumn{4}{|c|}{ Development } & \multicolumn{4}{|c|}{ Psychomotor } & \multicolumn{4}{|c|}{ Learning } \\
\hline $\mathbf{F}$ & Definidor & M & TIR & $\mathbf{F}$ & Definidor & M & TIR & $\mathbf{F}$ & Definidor & M & TIR \\
\hline 1 & Growth & 138 & 15 & 1 & Movement & 246 & 22 & 1 & Knowledge & 163 & 18 \\
\hline 1 & Stages & 120 & 20 & 1 & Motricity & 153 & 15 & 1 & School & 75 & 32 \\
\hline 1 & Physical & 107 & 24 & 1 & Development & 148 & 23 & 1 & To learn & 71 & 20 \\
\hline 1 & Maturation & 99 & 20 & 1 & Body & 108 & 27 & 1 & Memory & 56 & 17 \\
\hline 1 & Evolution & 94 & 12 & 1 & Fine motricity & 76 & 33 & 3 & To read & 56 & 38 \\
\hline 1 & Cognitive & 91 & 23 & 1 & Gross motricity & 68 & 33 & 1 & Experiences & 55 & 26 \\
\hline 1 & Social & 88 & 28 & 1 & Laterality & 57 & 28 & 1 & Skills & 47 & 30 \\
\hline 2 & Process & 78 & 18 & 5 & Difficulty & 54 & 38 & 2 & Information & 42 & 29 \\
\hline 1 & Psychomotor & 61 & 22 & 2 & Psychological & 54 & 42 & 1 & To know & 40 & 48 \\
\hline \multirow[t]{3}{*}{4} & Learning & 58 & 29 & 1 & Brain & 36 & 36 & 2 & Process & 38 & 24 \\
\hline & Valor J: 251 & Val & G: 8.00 & & Valor J: 241 & Valc & : 21.00 & & Valor J: 258 & & 12.50 \\
\hline & \multicolumn{3}{|c|}{ Dyslalia } & \multicolumn{4}{|c|}{ Dyslexia } & \multicolumn{4}{|c|}{ Dyscalculia } \\
\hline $\mathbf{F}$ & Definidor & $\mathbf{M}$ & TIR & $\mathbf{F}$ & Definidor & 197 & TIR & $\mathbf{F}$ & Definidor & M & TIR \\
\hline 2 & Language & 159 & 18 & 3 & To read & 224 & 21 & 1 & Numbers & 236 & 17 \\
\hline 1 & Phonemes & 157 & 17 & 1 & Writing & 178 & 19 & 1 & Math & 173 & 18 \\
\hline 5 & Difficulty & 150 & 18 & 5 & Difficulty & 171 & 13 & 5 & Disorder & 173 & 16 \\
\hline 5 & Disorder & 128 & 16 & 5 & Disorder & 157 & 14 & 5 & Difficulty & 142 & 17 \\
\hline 1 & Articulation & 104 & 25 & 1 & Letters & 107 & 22 & 1 & Subtraction & 89 & 34 \\
\hline 1 & Speech & 79 & 21 & 2 & Language & 88 & 22 & 1 & Addition & 83 & 33 \\
\hline 2 & Words & 65 & 26 & 4 & Learning & 78 & 37 & 1 & Arithmetic & 82 & 31 \\
\hline 2 & Problems & 53 & 26 & 2 & Words & 68 & 14 & 4 & Learning & 68 & 31 \\
\hline 1 & Pronunciation & 46 & 49 & 1 & Reading-writing & 59 & 30 & 2 & Problems & 65 & 20 \\
\hline 3 & To read & 45 & 17 & 1 & Omissions & 44 & 40 & 2 & Kids & 60 & 28 \\
\hline & Valor J: 262 & & G: 11.40 & & Valor J: 269 & Valc & : 18.00 & & Valor J: 286 & & 17.60 \\
\hline \multicolumn{4}{|c|}{ Attention-deficit } & \multicolumn{4}{|c|}{ Evaluation } & \multicolumn{4}{|c|}{ Diagnosis } \\
\hline $\mathbf{F}$ & Definidor & $\mathbf{M}$ & TIR & $\mathbf{F}$ & Definidor & $\mathbf{M}$ & TIR & $\mathbf{F}$ & Definidor & $\mathbf{M}$ & TIR \\
\hline 5 & Disorder & 193 & 16 & 2 & Diagnosis & 155 & 26 & 2 & Evaluation & 215 & 18 \\
\hline 1 & Hyperactivity & 175 & 21 & 3 & Tests & 151 & 21 & 3 & Tests & 153 & 23 \\
\hline 1 & Attention & 136 & 26 & 3 & Treatment & 75 & 35 & 3 & Treatment & 89 & 25 \\
\hline 5 & Difficulty & 134 & 18 & 3 & Interviews & 65 & 32 & 1 & Functional & 82 & 24 \\
\hline 4 & Learning & 68 & 33 & 1 & Observation & 63 & 31 & 2 & Results & 67 & 22 \\
\hline 1 & Distraction & 67 & 29 & 1 & Diagnostic & 52 & 17 & 2 & To evaluate & 63 & 17 \\
\hline 1 & Uneasy & 63 & 37 & 1 & Psychological & 44 & 33 & 5 & Disorder & 56 & 30 \\
\hline 2 & Kids & 60 & 34 & 2 & Analysis & 35 & 36 & 3 & Interviews & 45 & 40 \\
\hline 1 & Lack of attention & 49 & 23 & 2 & To evaluate & 30 & 28 & 1 & DSM-V & 41 & 45 \\
\hline 1 & Impulsiveness & 44 & 18 & 1 & Exam & 29 & 31 & 1 & Therapy & 36 & 45 \\
\hline \multirow{2}{*}{\multicolumn{4}{|c|}{$\begin{array}{r}\text { Valor J: } 242 \\
\text { Report }\end{array}$}} & & Valor J: 237 & \multicolumn{2}{|c|}{ Valor G: 12.60} & \multicolumn{4}{|c|}{ Valor G: 17.90} \\
\hline & & & & & & & & & & & \\
\hline $\mathbf{F}$ & Definidor & $\mathbf{M}$ & TIR & & & & & & & & \\
\hline 2 & Diagnosis & 180 & 31 & & & & & & & & \\
\hline 2 & Results & 168 & 19 & & & & & & & & \\
\hline 2 & Evaluation & 141 & 26 & & & & & & & & \\
\hline 3 & Tests & 126 & 21 & & & & & & & & \\
\hline 2 & Psychological & 124 & 17 & & & & & & & & \\
\hline 3 & Treatment & 66 & 27 & & & & & & & & \\
\hline 2 & Information & 58 & 36 & & & & & & & & \\
\hline 1 & A text & 56 & 22 & & & & & & & & \\
\hline 3 & Interviews & 51 & 17 & & & & & & & & \\
\hline 2 & Analysis & 48 & 23 & & & & & & & & \\
\hline
\end{tabular}


Furthermore, the constant nodes had changed their weight of relevance towards the end of the course. This change was heterogeneous through the targets. For example, development obtained a CVC of $41 \%$. In contrast, psychomotor obtained a CVC of $38 \%$. On another note, concerning the structural changes, three of the ten SAM groups (development, psychomotor, dyslalia) indicated a decrease in the $G$ value, which means the closeness of the definers in these three SAM groups had increased at the end of the course. In addition, five SAM groups showed a notable increase in the dispersion of their definers at the end of the course (dyslexia, report, dyscalculia, attention deficit, diagnosis), and two SAM groups had a tiny increase in the dispersion of the definers (learning, evaluation). In addition, there were changes in connectivity between the targets. Figure 2 shows the distribution of connections at the beginning and end of the course.

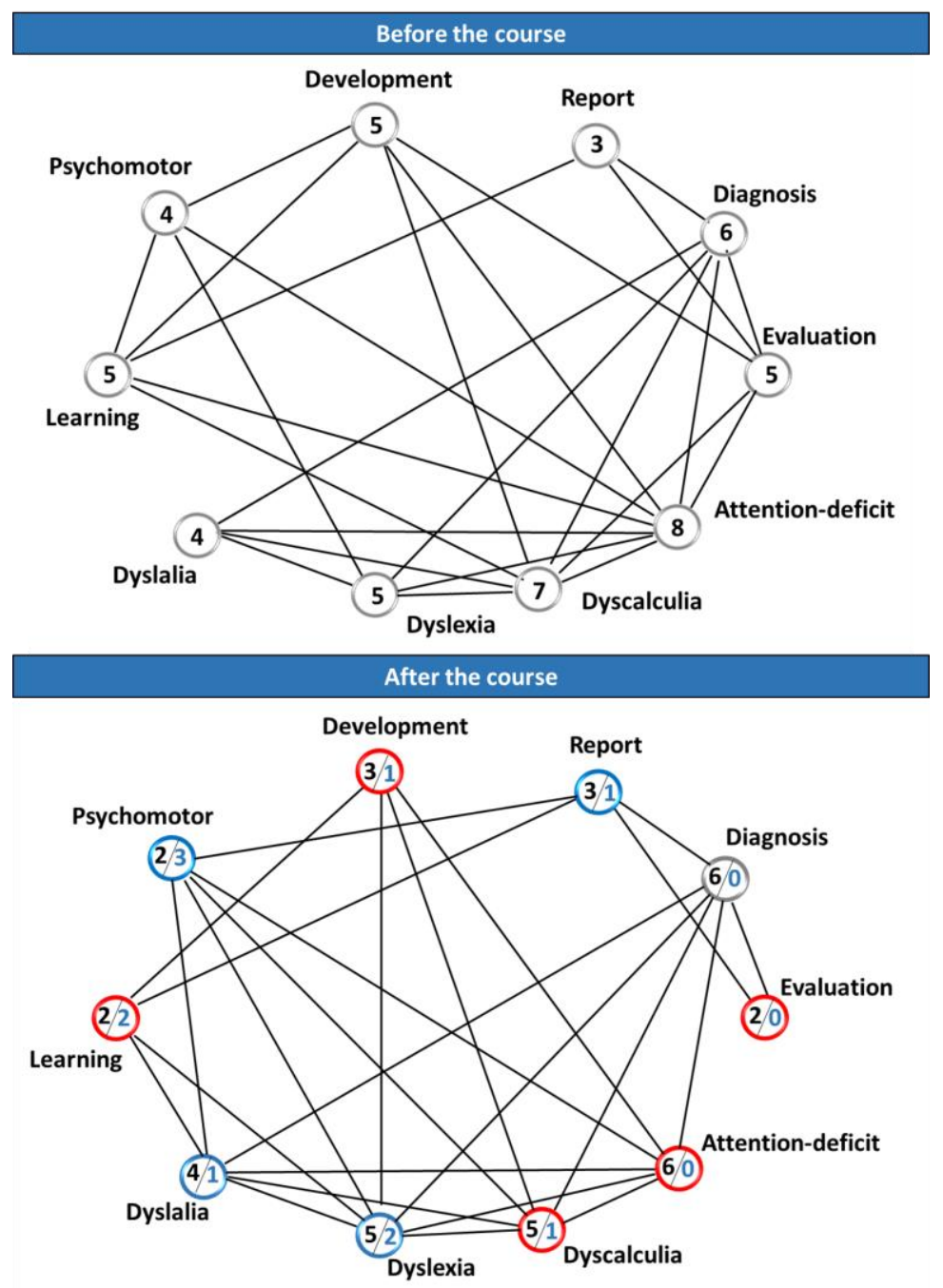

Figure 2: Changes in the number of connections among targets

Note: The number of connections for each conceptual node is reported with the number inside the circle. Furthermore, the connectivity graph after the course gives the number of constant connections (black number) and the new connections (blue number). Also, in the graph for after the course, three aspects of conceptual connectivity are reported: the fading of the initial target connections (red circles), the constancy in the number of target connections (gray circles), and the emergence of new target connections (blue circles). 
Dyscalculia is the target with the most connections and report is the target with least connections before the course. Meanwhile, at the end of course, the target with the highest number of connections was dyslexia, and evaluation had the lowest number of connections. Dyslexia was the target with the greatest number of new connections, and evaluation presented the lowest number of connections at the end of the course. Diagnosis, attention deficit, dyslexia, and dyscalculia were the targets that retained the number of connections presented in the initial NSNs. Evaluation was the target with the highest number of lost initial connections.

\subsection{Results from GEPHI Analysis}

The GEPHI analysis (Bastian et al., 2009) revealed changes in the conceptual organization of the NSNs at the end of the course (Figure 3). Before the course, the students had information about the subject, and they presented an organized pattern in terms of the relationships between the information nodes they had. At the beginning of course, students organized their knowledge schema into seven conceptual modules. The first one (purple colour) involved $31.43 \%$ of the NSNs definers (interview, questions, treatment, patient, information, evaluation, tests, result, results, distraction, concentration, hyperactivity, pronunciation, lack of attention, phonemes, speech, tongue, speech, development, attention, school). The main nodes in this module were problems and disorders. The second module (light green) included $22.86 \%$ of the definers (psychological, maturation, evolution, go forward, growth, physical, process, stages, exam, diagnosis, revision, to rate, knowledge). The nodes with more relevance in this group were skills and learning. The third module (light blue) included $15.71 \%$ of the definers (movement, body, motricity, mind, brain, motor, psychology, writing, letters, confusion), and the node with more connections was kids. The fourth module (orange) consisted of $10 \%$ of the definers (a text, summary, investigation, conclusion, reading, essay, data), and it was disconnected from the NSNs. The fifth module (coffee) contained $7.14 \%$ of the definers (difficulty, language, numbers, to read, words). The sixth module (pink) incorporated $7.14 \%$ of the definers (to learn, memory, education, study, knowledge). The last module (dark green) integrated $5.71 \%$ of the definers (addition, subtraction, operation, math). At the end of the course, students grouped the NSNs definers into nine conceptual modules. The first group (purple) included $21.74 \%$ of the definers (psychomotor, physical, cognitive, maturation, social, stages, growth, to read, words, language, problems, kids, evolution, problems), and the more relevant nodes were learning and process. The second module (green) included $20.29 \%$ of the definers (lack of attention, uneasy, election, impulsiveness, distraction, hyperactivity, disorder, functional, articulation, DSM-IV, phonemes, speech, pronunciation), and the node with more connections was disorder. The third module (light blue) comprised $14.49 \%$ of the definers (information, evaluation, results, psychological, treatment, analysis, interviews, test, diagnosis, evaluate), and the main node was kids. The fourth module (coffee) contained $13.04 \%$ of the definers (brain, motricity, laterality, gross motricity, body, development, fine motricity, movement), and the most salient node was difficulty. The fifth module (orange) included $10.14 \%$ of the definers (knowledge, skill, school, memory, experiences, to learn, to know). The sixth group (pink) included $7.25 \%$ of the definers (numbers, subtraction, math, addition, arithmetic). The seventh module (dark green) included $5.8 \%$ of the definers (writing, letters, omissions, reading, writing). The eighth group (pale pink) involved $5.8 \%$ of the definers (diagnosis, observation, 
exam, psychological), and it was separated from the NSNs; finally, the last group (gray) contained just $1.45 \%$ of the definers (a text).

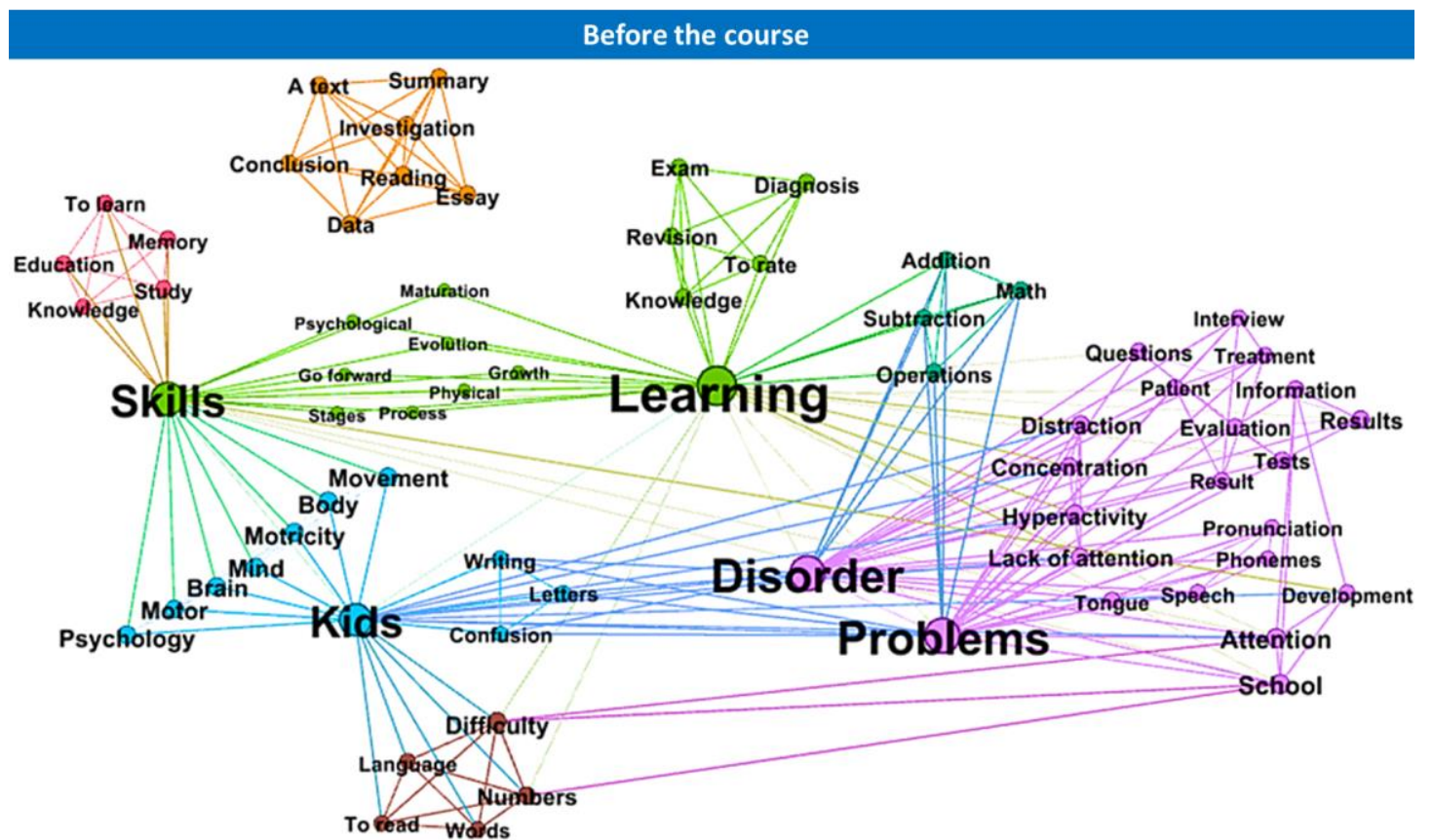

After the course

Knowledge

Skills Memory

Experiences To learn
To know

Process

Psychomotor

A text

Maturation Physical Cognitive Words

Social Stages Growth To read

Diagnosis

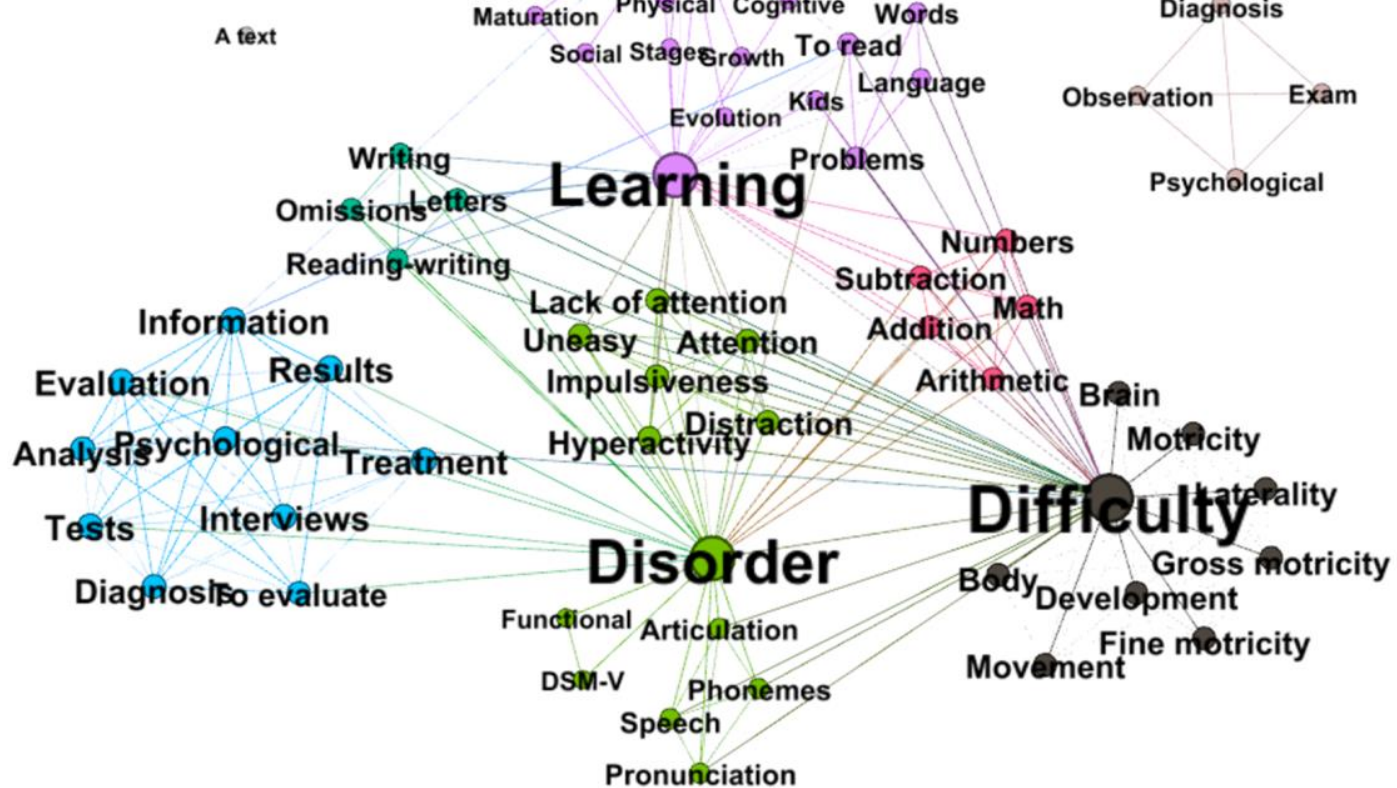

Figure 3: Before and after of the course: GEPHI analysis

Note: Each conceptual module obtained by GEPHI from NSNs is represented by a colour. 
Furthermore, the organization of concepts and the meaning of several conceptual nodes had changed at the end of the course. For example, the definer difficulty attained greater centrality during the second part of the course. This result may indicate that the students had re-signified this concept based on the knowledge they acquired. At the beginning of the course, difficulty was grouped with nodes associated with general areas (language, numbers, words, reading) in which children may present learning difficulties during their development. Meanwhile, at the end of the course, difficulty was grouped with words of a more sophisticated level related to the etiology of these difficulties (brain), the specific areas of development (fine motor, gross motor, laterality) and was also connected to broader spectrum concepts (development or body). Figure 5 illustrates the change in connectivity for the definer difficulty.

Before the course

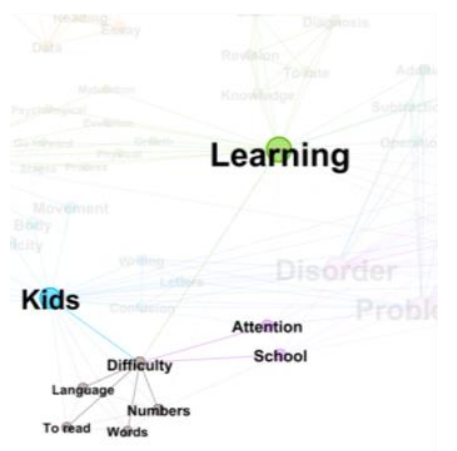

After the course

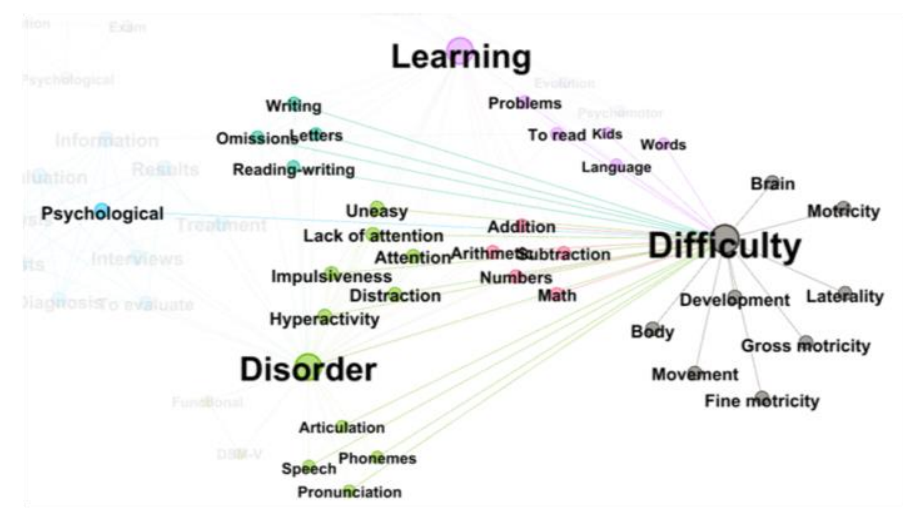

Figure 5: Change in connectivity for the definer difficulty

\section{Discussion}

Learning assessment is one of the most significant twenty-first--century classroom challenges. UNESCO (2015) noted that the effectiveness of evaluation tools depends on taking account of the purpose, scope, nature, impact, and level of evaluation in their design. In this regard, this work has demonstrated the effectiveness of constructive cognitive assessment to obtain information about students' state of knowledge before and after a course. For this, the authors applied the NSNs technique to measure the changes in the organization and structure of the knowledge schema for the diagnostic evaluation of learning disorders. The authors explored three aspects of cognitive learning, the first referring to the conceptual content that the students had in their memory about the course, the second relating to the conceptual structure interpreted as the arrangement between the conceptual nodes of the natural semantic network, and the third concerning the general meaning that results from the combination of conceptual content and its organization and structure.

The results indicated that students entered the course with prior knowledge about the topic. These results are similar to those of the study by Urdiales-Ibarra et al. (2018) in biology and Morales-Martinez, Lopez-Perez, et al. (2020), and MoralesMartinez et al. (2021) in psychology. The role of these pre-schemas in academic 
learning has not been widely discussed from the cognitive perspective of knowledge mental representation. Figueroa-Nazuno (2007) mentioned that people construct and reconstruct meanings based on what is in their memory. Thus, the authors hypothesize that these previous cognitive structures are a primary mechanism of knowledge construction. Students use pre-schemas to have cognitive coherence and to create a more efficient learning path. Based on HIP, the participants used their previous schemas to assimilate and accommodate new knowledge; therefore, they probably used a top-down processing style predominantly to manage the information in their memories. There is not enough information to know if this kind of processing is apparent among beginners.

A comparison of the conceptual content in Tables 1 and 2 indicates a relevant change in the degree of generality of the NSNs. The initial schema included general concepts connected to the NSNs throughout a psychology macro-schema; additionally, students used common sense to build this seminal schema. However, these concepts were not associated in a strict sense with the content of the course. For example, at the beginning of the course, students defined development alongside concepts taken from a general psychology schema (e.g., psychological) or inferred by common sense (e.g., skills). Meanwhile, at the end of the course, students had eliminated these definers and included more specific concepts such as cognitive, social, and psychomotor. According to Marzano and Pickering's learning model (1997), these results suggest that the course's learning experiences influenced the dimension of the refinement of the information in the memory of these students.

Another aspect that the reader can observe in Tables 1 and 2 is the absence of examples to define the targets. The use of examples is common among students who are beginners in the study of a specific topic. For example, Morales-Martinez et al. (2021) reported that at the beginning of a course on human cognition, psychology students used many examples to define the concept of cognition. This result can be associated with the students' initial expertise level on the subject. So, in the present study, the kinds of concepts used in the initial NSNs suggest that the participants had at least some knowledge on the subject, although the knowledge schema they had at the beginning of the course was quite general. In fact, according to their career curriculum, students had received some information on the subject from previous courses.

In addition, some concepts showed greater conceptual constancy (Tables 1 and 2). For example, the target $d y$ slalia retained $90 \%$ of its definers in the final SAM group, while evaluation had retained only $30 \%$ of its definers by the end of the course. Although there is no theoretical discussion about the meaning of conceptual constancy, the authors hypothesize that the constancy of a definer in the NSNs over time is related to the condition of necessity or sufficiency of the definer in defining the target. If the definer is an indispensable or central property of the target, this will be presented constantly overtime in the NSNs. On the other hand, conceptual migration (elimination of conceptual nodes) may be related to circumstances when the initial nodes are not indispensable attributes for the concept; then the definer appeared incidentally in the initial NSNs. For example, 
when the definers are part of a macro schema of knowledge and this schema is the only conceptual resource that students have, these general definers will appear in the NSNs while the schema evolves towards a more sophisticated one. In addition, a high CC may suggest that the target presents invariance of meaning; thus, the greater the invariance of meaning, the lower the level of flexibility in terms of the schema being modified by new incoming information. In this study, the objectives with the highest CC were dyslalia, attention deficit, dyscalculia, dyslexia, and development; therefore, these targets underwent less migration or conceptual change. The authors suggest that the conceptual stability of these targets could be related to the type of schemata; if a target is clearly defined (classic schemata) or there are clear guides to identify its conceptual properties (probabilistic schemata), then the constancy of definers increases. There is agreement about which characteristics are necessary and sufficient to define learning disorder in psychology. If students learn the criteria to diagnosis these conditions from standardized diagnostic manuals (e.g., Diagnostic and Statistical Manual of Mental Disorders), they demonstrated major consensus in their definitions across time. The second factor influencing the CC could be that students were familiar with these five topics since they had reviewed this knowledge domain throughout their entire academic training. The opposite happened with evaluation, which was the target with the lowest CC, and which therefore underwent greater modification in its final NSNs group. These results support the authors' idea that when a student is a beginner in a certain subject, knowledge schemas can be more flexible, and therefore, these structures can be more easily modified through learning experiences. As students gain more knowledge of a topic, their flexibility in terms of the schemas may decrease, and the stability of the schema may increase.

On the other hand, the constructive cognitive evaluation explored the structural characteristics of the knowledge schema that the students constructed during the course. The G value indicates the dispersion between the concepts of the NSNs; in this regard, the reader can observe in Tables 1 and 2 that the target development showed a marked decrease in the dispersion of the defining concepts, while report and dyslexia markedly increased their dispersion. Interpreting these results is not an easy task, given that there is no detailed description of the meaning of network dispersion or density from the field of mental representation of cognitive psychology (e.g., Figueroa et al., 1976; Lopez et al., 2014; Morales-Martinez, Angeles-Castellanos, et al., 2020; Morales-Martinez et al., 2021; Urdiales-Ibarra et al., 2018).

The authors suggest that the $G$ values may indicate the degree of similarity among the definers concerning the conceptual belonging they have regarding the target. Low $G$ values could suggest a major homogeneity in definers in defining the concept, while high values may indicate greater variability in the degree to which each definer conceptually typifies a target. The reasons for the changes in $G$ values are unknown; the decrement in this NSNs dispersion could suggest that the learning experiences increase the quality of the selection process for definers. Therefore, the closeness of meaning among these definers increase. Another possibility is that learning experiences influence the valuation process for the 
grade of relatedness among definers and their target because students acquire abilities to find relations among the definers and their targets.

Concerning the pattern of connections between the targets for the NSNs, the results indicated that the targets related to disorders were the most stable in terms of the number of connections and the kind of definers involved in these connections. Since there are few reports about the cognitive nature of NSNs connectivity, it is difficult to explain these results from the cognitive perspective of mental representation. For example, Morales-Martinez et al. (2021) reported on the NSNs connectivity of anatomy in students who did not achieve a passing grade in this subject; however, they did not provide information about the cognitive nature of the connection pattern. In this study, the authors suggest that the persistence of the connection of the schema structure over time could relate to the level of expertise demonstrated by a student. Since, participants in this study had read on learning disorders, they could have formed a schema of this subject very early in their academic development. Then, their NSNs on this topic had well established connections.

The third dimension of analysis was related to the meaning of the NSNs. The analysis of the CVC values suggested that the readings reviewed during the course changed the perception that students have about the relevance of the conceptual nodes for the NSNs. The CVC of the definers with CC has not been discussed in any article on constructive cognitive assessment (e.g., MoralesMartinez et al., 2021; Morales-Martinez, Angeles-Castellanos, et al., 2020; MoralesMartinez, Lopez-Perez, et al., 2020; Urdiales-Ibarra et al., 2018). The authors propose that the CVC value may reflect the cognitive flexibility of the schema in terms of conceptual valuation. If the definers with CC are cognitively permeable to the input of new information, they can change their relevance values through a revaluation process given the new information entering the schema and the new relationships established. Therefore, when CVC is high, the best chance of increasing the students' learning rate is by presenting novel information in the form of new conceptual nodes, new conceptual relationships, and new forms by which to interpret and use information.

In addition, the GEPHI analysis indicated an essential change in the meaning attributed to learning disorders; at the beginning of the course, the students had learning, disorder, problems, and skills as central nodes, while at the end of the course, the central nodes were learning, disorder and difficulty. The definer difficulty replaced problems; this suggests that the students changed their vision towards a more proactive view of diagnosing and treating learning difficulties. However, since the centrality of skills disappeared, evaluation and diagnosis represented a focus on what is missing or damaged (difficulties and disorders), and thus, the conceptualization of diagnosis continues to be driven by the medical model of disease.

Finally, the organization of initial definers suggests that the students had a general idea about assessing and diagnosing learning disorders. They established relationships between the definers in relation to their general knowledge about 
development and learning. At the end of the course, the students had integrated new information nodes into their knowledge schema, refined the organization of the concepts with CC, and extended their schema with new relationships between the definers (Figure 4). For example, the definer difficulty at the beginning of the course was not central to the NSNs, and its relationships were very general. This definer was connected with concepts of a vague conceptual spectrum for the course (e.g., learning, children, school), and it was connected with only a handful of the distinctive features of learning difficulties (e.g., language, numbers, words, reading). At the end of the course, difficulty acquired greater richness in terms of its conceptual definition and conceptual relationships with other definers (Figure $5)$.

In general, transformations in the participants' knowledge schema in the three levels analyzed -content, structure, and organization - were apparent. So, in this work, the evidence supports the idea that constructive cognitive assessment effectively diagnoses cognitive changes due to learning. The findings in this research have implications at the theoretical level since there is currently little information available about the cognitive mechanism underlying the development of cognitive structures in academic environments. At a methodological level, empirical evidence about the effectiveness of NSNs as a cognitive approach to evaluate academic learning has been presented in this study. Furthermore, at the level of application, this study provides an alternative tool and cognitive indicators for learning that are useful for formative assessment or assessment for learning.

However, since the sample in this study was very small, and there was not a control in the instructional sequence, future research should include comparison and control groups, to explore the effects of teaching strategies. Additionally, it would be very interesting to contrast the quality of organization, structure, and content of knowledge schema based on the academic levels of students. Many other variables and manipulations could be introduced to enhance our comprehension of declarative learning and the formation of cognitive knowledge structures in an academic environment (e.g., induvial characteristics, type of institution, nature of content).

\section{Conclusion}

In sum, this study has offered empirical evidence of the cognitive changes that occur in cognitive structures of knowledge due to the academic learning process. The results indicated that constructive cognitive assessment is helpful in terms of measuring cognitive expressions of learning. For example, in this study, it was possible to identify the changes in the configuration of cognitive schemas for knowledge, changes in the conceptual content, and modifications in the relationships among the conceptual nodes that students had assimilated in their memories due to learning. Thus, cognitive assessment tools such as NSNs are an effective means for diagnosing, monitoring, and evaluating the learning process. Furthermore, the data obtained with this type of tool can be used to improve or generate new teaching strategies adapted to the cognitive characteristics of students. 
Mapping the state of students' knowledge gives valuable information about the difficulties that students have in learning material whether due to theoretical confusions, problems in semantic understanding, or difficulties with the structure of information. This kind of cognitive diagnosis will allow teachers to design learning materials and strategies that increase the clarity of the concepts presented in classes. These actions will help students adequately discriminate the conceptual categories presented and achieve significant clarity about their knowledge. However, to implement this type of proposal, it is necessary to continue exploring the benefits and limitations of using cognitive learning assessment tools and to continue the search to establish cognitive measurement parameters that are useful for improving teaching and learning processes.

\section{References}

Arieli-Attali, M. (2013, October 20-25). Formative assessment with cognition in mind: The cognitively based assessment of, for and as learning [Paper presentation]. 39th Annual Conference: Educational Assessment 2.0: Technology in Educational Assessment, Tel Aviv, Israel.

Bastian, M., Heymann, S., \& Jacomy, M. (2009, May 17-20). Gephi: an open-source software for exploring and manipulating networks [Paper presentation]. Association for the Advancement of Artificial Intelligence, Third International AAAI Conference on Weblogs and Social Media, San Jose California, United States.

El-Yassin, H. D. (2015). Integrated assessment in medical education. Journal of Contemporary Medical Sciences, 36-38. http://www.jocms.org/index.php/jcms/article/view/51

Figueroa, J. G., González, E. G., \& Solís, V. M. (1976). An approach to the problem of meaning: Semantic networks. Journal of Psycholinguistic Research, 5(2), 107-115. https:/ / doi.org/10.1007/BF01067252

Figueroa-Nazuno, J. G. (2007, October 24-25). El significado de las Redes Semánticas Naturales: Y la tradición oral, 20 años después [The meaning of Natural Semantic Networks: And oral tradition, 20 years later] [Paper presentation]. Primer Simposium Internacional: Cognición y Representación del Conocimiento. Monterrey, Nuevo León, México.

Lopez, E. O. (1996). Schematically Related Word Recognition (Publication No. 9613356) [Doctoral dissertation, University of Wisconsin-Madison]. ProQuest Dissertations \& Theses Global.

Lopez-Ramirez, E. O., \& Morales-Martinez, G. E. (2019). Learning's constructivechronometric cognitive assessment model [Unpublished manuscript]. Institute of Research on the University and Education, National Autonomous University of Mexico.

Lopez, E. O., \& Theios, J. (1992). Semantic analyzer of schemata organization (SASO). Behavior Research Methods, Instruments, $\mathcal{E}$ Computers, 24(2), 277-285. https:/ / doi.org/10.3758/BF03203508

Lopez, E. O., Morales, G. E., Hedlefs, I., \& Gonzalez, C. J. (2014). New empirical directions to evaluate online learning. International Journal of Advances in Psychology, 3(2), 40-47. https://doi.org/10.14355\&ijap.2014.0302.03

Marzano, R. J., \& Pickering, D. J. (1997). Dimensions of learning: Teacher's manual (2nd ed.). ASCD.

Messick, S. (1984). The psychology of educational measurement. Journal of Educational Measurement, 21(3), 215-237. https:/ / doi.org/10.1111/j.1745-3984.1984.tb01030.x

Morales-Martinez, G. E. (2015). Protocolo para la recolección de conceptos objetivo y definidores centrales y diferidos (PRECODECD): Un sistema de codificación de conceptos extraídos de las redes semánticas naturales [Protocol for the collection of objective concepts 
and central and deferred definers (PRECODECD): A coding system for concepts extracted from natural semantic networks] [Unpublished manuscript]. Institute of Research on the University and Education, National Autonomous University of Mexico.

Morales-Martinez, G. E. (2020). Sistema de evaluación cognitiva constructiva cronométrica del aprendizaje en línea y presencial [Online and face-to-face learning's constructivechronometric cognitive assessment system] [Manuscript submitted for publication]. Institute of Research on the University and Education, National Autonomous University of Mexico.

Morales-Martinez, G. E., Ángeles-Castellanos, A. M., Ibarra-Ramírez, V. H., \& ManceraRangel, M. I. (2020). Cognitive e-tools for diagnosing the state of medical knowledge in students enrolled for a second time in an anatomy course. International Journal of Learning, Teaching and Educational Research, 19(9), 341-362. https://doi.org/10.26803/ijlter.19.9.18

Morales-Martinez, G., \& Lopez-Ramirez, E. (2016). Cognitive responsive e-assessment of constructive e-learning. Journal of e-Learning and Knowledge Society (Je-LKS), 12(4), 39-49. http://www.je-lks.org/ojs/index.php/Je-LKS_EN/article/view/1187

Morales-Martinez, G. E., \& Lopez-Ramirez, E. O. (2018a). EVCOG Modulo 1. Configurador RSN [EVCOG Module 1. NSN Configurator] (Version 1.1.) [Computer software]. Registro Público del Derecho de Autor. 03-2018-111311554300-01

Morales-Martinez, G. E., \& Lopez-Ramirez, E. O. (2018b). EVCOG Modulo 2. Capturador RSN [EVCOG Module 2. NSN Data storage] (Version 1.1.) [Computer software]. Registro Público del Derecho de Autor. 03-2018-1113115235001

Morales-Martinez, G. E., \& Lopez-Ramirez, E. O. (2018c). EVCOG Modulo 3. Editor RSN [EVCOG Module 3. NSN Editor] (Version 1.1.) [Computer software]. Registro Público del Derecho de Autor. 03-2018-1113115235001

Morales-Martinez, G. E., \& Lopez-Ramirez, E. O. (2018d). EVCOG Modulo 4. Análisis RSN [EVCOG Module 4. NSN Analysis] (Version 1.1.) [Computer software]. Registro Público del Derecho de Autor. 03-2018-1113115235001

Morales-Martínez, G. E., López-Ramírez, E. O., Castro-Campos, C., Villarreal-Treviño, M. G., \& Gonzales-Trujillo, C. J. (2017). Cognitive analysis of meaning and acquired mental representations as an alternative measurement method technique to innovate e-assessment. European Journal of Educational Research, 6(4), 455-464. https://www.eu-jer.com/EU-JER_6_4_455_Morales-Martinez_etal.pdf

Morales-Martinez, G. E., Lopez-Ramirez, E. O. \& Lopez-Gonzalez, A. E. (2015). New approaches to e-cognitive assessment of e-learning. International Journal for eLearning Security (IjeLS), 5(2), 449-453. https:// doi.org/10.20533/ijels.2046.4568.2015.0057

Morales-Martinez, G. E., Mezquita-Hoyos, Y. N., Gonzalez-Trujillo, C. J., Lopez-Ramirez, E. O., \& Garcia-Duran, P. J. (2018). Formative e-assessment of schema acquisition in the human lexicon as a tool in adaptive online instruction. In R. Lopez-Ruiz (Ed.), From natural to artificial intelligence: Algorithms and application (pp. 69-88). IntechOpen. http://doi.org/10.5772/intechopen.81623

Morales-Martínez, G. E., López-Pérez, R. M., García-Collantes, A., \& López-Ramírez, E. O. (2020). Evaluación constructiva cronométrica para evaluar el aprendizaje en línea y presencial [Constructive-chronometric evaluation as a tool to evaluate online and face-to-face learning]. Tecnología, Ciencia y Educación, 15(1), 105-124. https://www.tecnologia-ciencia educacion.com/index.php/TCE/article/view/371

Morales-Martinez, G. E., Trejo-Quintana, J., Charles-Cavazos, D. J., Mezquita-Hoyos, Y. N., \& Sanchez-Monroy, M. (2021). Chronometric constructive cognitive learning evaluation model: Measuring the construction of the human cognition schema of 
psychology students. International Journal of Learning, Teaching and Educational Research, 20(2), 1-21. https:// doi.org/10.26803/ijlter.20.2.1

Sadeghi, K., \& Rahmati, T. (2017). Integrating assessment as, for, and of learning in a largescale exam preparation course. Assessing Writing, 34, 50-61. https://doi.org/10.1016/j.asw.2017.09.003

United Nations Educational Scientific and Cultural Organization (2015). Rethinking education: Towards a global common good? https://unesdoc.unesco.org/ark:/48223/pf0000232555

Urdiales-Ibarra, M. E., Lopez-Ramirez, E. O., Castro-Campos, C., Villarreal-Treviño, M. G., \& Carrillo-Colon, J. E. (2018). Biology schemata knowledge organization and meaning formation due to learning: A constructive-chronometric approach to concept mapping usability. Creative Education, 9(16), 2992-2706. https:// doi.org/10.4236/ce.2018.916203

Wiliam, D. (2011). What is assessment for learning?. Studies in Educational Evaluation, 37(1), 3-14. https://doi.org/doi:10.1016/j.stueduc.2011.03.001 